Reversing Implicit First Impressions through Reinterpretation after a Two-Day Delay

\author{
Thomas C. Mann and Melissa J. Ferguson \\ Cornell University
}

Manuscript word count: 4977/5000

Author Note

Thomas C. Mann and Melissa J. Ferguson, Department of Psychology, Cornell University.

This research was supported by National Institutes of Health grant 1R21AG042662-01A1 awarded to M. J. Ferguson, and a National Science Foundation Graduate Research Fellowship awarded to T. C. Mann.

Correspondence concerning this article should be addressed to Thomas C. Mann, Department of Psychology, Cornell University, 211 Uris Hall, Ithaca, NY 14853. E-mail: tcm79@cornell.edu

Melissa J. Ferguson, Department of Psychology, Cornell University, 211 Uris Hall, Ithaca, NY 14853. E-mail: melissaferguson@cornell.edu 


\begin{abstract}
People are adept at forming impressions of others, but how easily can impressions be updated? Although implicit first impressions have been characterized as difficult to overturn, recent work shows that they can be reversed through reinterpretation of earlier learning. However, such reversal has been demonstrated only in the same experimental session in which the impression formed, suggesting that implicit updating might be possible only within a brief temporal window, before impressions are consolidated and when memory about the initial information is strongest. Implicit impressions may be unable to be revised when reinterpreting details are learned later, due to memory consolidation or forgetting of the details to be reinterpreted. This study tested whether implicit first impressions can be reversed through reinterpretation after a two-day delay following the initial formation. Results showed that implicit revision emerged after the delay, even among those with poor explicit recall or who were not cued to recall. We discuss implications for theory on impression formation and updating.
\end{abstract}

Keywords: implicit evaluation; first impressions; AMP; reinterpretation; attitudes; recall 


\section{Reversing Implicit First Impressions through Reinterpretation after a Two-Day \\ Delay}

People are adept at making inferences about other people based on even minimal information, such as brief descriptions of single behaviors (Todorov \& Uleman, 2002), facial characteristics (Rule et al., 2010), and group membership (Devine, 1989). These impressions have consequences for judgments and interpersonal behavior, and persist even when the initial information can no longer be recalled (e.g., McCarthy \& Skowronski, 2011; Todorov \& Uleman, 2002). But what happens when first impressions are wrong? Is it true that we "never get a second chance to make a first impression"? First impressions that are activated implicitly (unintentionally), rather than explicitly (intentionally), indeed have been repeatedly portrayed as more difficult to undo (Gregg et al., 2006; McConnell \& Rydell, 2014; Wilson, Lindsey, \& Schooler, 2000). Explanations for this dissociation vary, but a common proposal is that implicit evaluations are primarily driven by slow-changing associations, which are less sensitive to propositional processing - suggesting that first impressions that have been explicitly rejected might continue to implicitly guide behavior (e.g., Rydell \& McConnell, 2006).

Recent work, however, indicates that implicit impressions can be rapidly reversed. First, theoretical models and data have increasingly supported the idea that propositional thinking can impact implicit processes (e.g., De Houwer, 2014; Gawronski \& Bodenhausen, 2006; Wyer, 2010, 2016), questioning the view that implicit impressions must be inherently slow to change. For example, although approach-avoidance behaviors can impact implicit evaluations of stimuli (e.g., Kawakami, Phills, Steele, \& Dovidio, 2007; Woud, Maas, Becker, \& Rinck, 2013), merely instructing participants about 
approach-avoidance contingencies can similarly impact implicit evaluations (Van Dessel, De Houwer, Gast, \& Smith, 2015; Van Dessel, De Houwer, Gast, Smith, \& Schryver, 2016). In the context of impression change, these ideas suggest that revision of implicit impressions may be strongest when new information is subjectively assessed as more diagnostic or important (though even propositional information that is seemingly low in diagnosticity may sometimes drive change; Van Dessel et al., 2016). In support of this possibility, Cone and Ferguson (2015) asked participants to read 100 behavioral statements about a novel person that indicated his overall goodness, and formed implicit positive impressions of him. After then learning an additional behavior that was extremely negative (e.g., that he had molested children), participants showed robust revision, switching to a strongly negative implicit impression of him. Furthermore, the perceived offensiveness of the single negative action predicted the extent of revision, and this effect was mediated by the perceived diagnosticity of the actions (i.e., how much the behavior was assumed to reflect the target's true character).

It may be harder, however, to revise an initially negative implicit impression to a positive one in this way, in that negative information is viewed as particularly diagnostic (Skowronski \& Carlston, 1989). In their work, Cone and Ferguson (2015) in fact did not find reversal after participants learned that an initially negative person also performed an extremely positive behavior (donating a kidney to a sick child). However, another set of studies (Mann \& Ferguson, 2015) showed that revising even an initial negative implicit impression is possible. Namely, participants who learned new information that changed the evaluative meaning of the initial information showed strong implicit revision: when participants read about a man who broke into and damaged his neighbor's homes, the 
ensuing negative implicit impression was reversed by the discovery that he was actually rescuing children from a fire. The degree of updating was predicted by participants' selfreported extent of reinterpretation. Other work has also shown that when new information is presented that updates previously learned details, implicit evaluations are likely to be revised when participants can elaborate on the earlier information (Wyer, 2010). This suggests that reinterpretation may be a powerful route through which even negative implicit first impressions can be reversed.

\section{A Brief Window of Opportunity for Implicit Revision through Reinterpretation?}

One major limitation of existing work on reinterpretation (Mann \& Ferguson, 2015; Wyer, 2010), as well as all other work showing implicit revision of first impressions toward novel targets (Cone \& Ferguson, 2015; Peters \& Gawronski, 2011; Wyer, 2016), is that in all cases the new evidence is presented mere minutes after the first impressions have formed. Thus, even though new information that reinterpreted the meaning of a first impression was successful in "undoing" implicit first impressions in a single lab session (Mann \& Ferguson, 2015), it is possible that implicit revision can occur only within this kind of short temporal window (see Peters \& Gawronski, 2011), which would considerably limit the circumstances in which implicit impressions can be updated. Why might revision through reinterpretation be possible only within such a brief temporal window? There are at least two lines of work that are relevant. First, as time elapses after the first impression has formed, memory for the details of the initial information should subside, potentially undermining revision. The details underlying one's initial impression are often less impactful on judgment over time as more information about a person is learned, with such judgments about the subject of an 
impression becoming increasingly based on trait abstractions more than recall of specific behaviors (e.g., Klein, Loftus, Trafton, \& Fuhrman, 1992; Sherman \& Klein, 1994; see also Hastie \& Park, 1986). There is sometimes even stronger recall for behaviors that contradict one's overall impression than for behaviors that are consistent with it (e.g., Babey, Queller, \& Klein, 1998; Hastie \& Kumar, 1979), as the efficiency gains of reliance on schemas renders continued use of memories for consistent behaviors less necessary. Indeed, first impressions persist and continue to impact how people respond to others even after the initial behavioral information is forgotten (Castelli et al., 2004; McCarthy \& Skowronski, 2011; Todorov \& Uleman, 2002).

Efficiency from abstraction, however, may have a cost. In particular, revision of impressions through reinterpretation may require recall of the specific behaviors that led to their formation in the first place (Wyer, 2010, 2016). Precisely because the subjective diagnosticity of new information is crucially important in predicting the impact of that information on impressions (Skowronski \& Carlston, 1989), people may be skeptical of new information that contradicts an earlier impression if they cannot recall its initial source. If earlier source memories have been forgotten but a person nonetheless retains the corresponding impression they formed on the basis of those memories, how can one compare the strength of the original and new information? This should be particularly difficult when the new information hinges on a reinterpretation of earlier details. Following this logic, reinterpretation may lead to updating only when one can connect the new details to the initial information. If we find this to be true in the present work, it would reveal an important limitation of trait abstraction in impression formation: a 
subsequent impairment in the capacity for revision, perhaps through reinterpretation in particular.

A second line of work suggesting that revision may be unlikely after time has elapsed concerns memory consolidation. Implicit impressions should consolidate over time, such that the representations may become less susceptible to interference through processes occurring over multiple timescales (Dudai, 2004; McGaugh, 2000). This would suggest that implicit first impressions become more difficult to revise once they have consolidated. Notably, this remains untested, as all research to date examining updating of implicit first impressions of novel targets has demonstrated such change before memory consolidation would be expected (i.e., within a 30-minute experiment; e.g., Cone \& Ferguson, 2015; Mann \& Ferguson, 2015; Peters \& Gawronski, 2011; Wyer, 2010, 2016). Finding that even information that directly bears on - and reverses - the evaluative implications of earlier learning fails to update implicit evaluations after two days would expand on recent findings that a delay of even minutes makes effective updating of implicit impressions less likely (Peters \& Gawronski, 2011; see also Zanon, De Houwer, Gast, \& Smith, 2009).

\section{Implicit Revision After A Delay}

Although some work suggests that implicit revision may be unlikely after a delay of multiple days, other work suggests that it might emerge. Namely, implicit evaluative impressions may be more reflective of recent rather than older experiences (Castelli, Carraro, Gawronski, \& Gava, 2010; cf. Dunham, Baron, \& Banaji, 2008; Rudman, Phelan, \& Heppen, 2007; Zanon et al., 2009). For example, Castelli and colleagues 
(2010) found that participants' self-reported recent (versus childhood) experiences, behaviors, and feelings about religion predicted their implicit evaluations of religion. Other research in cognitive psychology and cognitive neuroscience research shows that consolidation is not entirely unidirectional. A limitation of extinction and counterconditioning training for aversive memories is that once such initial memories are consolidated, new countervailing learning often is encoded into a separate memory trace, and thus does not replace the earlier memory (e.g., Bouton, 1994; see also Gawronski \& Cesario, 2013). Recent work on reconsolidation, however, has shown that reactivation of memories produces instability that enables modification (e.g., Agren et al., 2012; Lane et al., 2015; Schiller, Kanen, LeDoux, Monfils, \& Phelps, 2013; Schiller et al., 2010). Schiller and colleagues (2010), for example, found that only when participants were reminded of a conditioned stimulus 10 minutes prior to extinction training did the extinguished response fail to reappear a day or even a year later. The plasticity of consolidated memories after reminders thus opens the door to updating even after considerable time has passed. Furthermore, it may be the case that reinterpretation is particularly likely to result in the new information being integrated into the mental representation of the initial impression, rather than result in a separate, contextualized representation (Gawronski \& Cesario, 2013), given the direct relevance of the new information to the old. ${ }^{1}$

\section{Overview of Current Work}

In the current study, we tested whether implicit evaluative impressions of a novel person could be reversed by new information learned two days after formation. We led participants to form a negative impression of a target, and then introduced (after two 
days) new details that either did or did not reframe those actions as positive. We measured implicit evaluations of the target after both sets of information.

We also examined the role of recall in revision through reinterpretation after delay. In order for revision to ensue, perhaps especially after consolidation, it may be necessary to be able to explicitly recall (and reconsider) a considerable amount of the initial information (Wyer, 2010, 2016), or to at least be prompted to remember the details. In contrast, if implicit revision is robust, it may emerge regardless of explicit memory for the details of the initial information. To test this question, we manipulated whether participants completed a memory quiz before they received the new information in the second session.

\section{Method}

\section{Participants}

Four hundred seventy-two participants were recruited from Mechanical Turk (mturk.com) in exchange for $\$ 1.00$ for completing the first session and $\$ 0.50$ for completing the second session. We determined through a power analysis to recruit enough participants to achieve a sample of approximately 260 participants at Time 2 for $80 \%+$ power to detect a medium-small (Cohen's $d=.25$ ) four-way mixed interaction effect. ${ }^{2}$ Participants were recruited in batches of 50-117 over approximately one month until we exceeded our target Time 2 sample size (this was our stopping rule). These small batches allowed us to monitor attrition and ensure that all participants in a batch would finish the first session within hours of each other, making it possible for the mass invitation for session 2 to be sent approximately two days later for all participants. Five participants failed to complete the first session, and partial data from 2 were lost due to 
server error, so they were excluded from all analyses. Of those who completed Session 1, 62\% (289 participants) completed the second session. Data from 5 participants fluent in Mandarin or Cantonese, and 14 participants who used solely one response key on every trial of at least one administration of the implicit measure (Payne et al., 2005), were excluded from all analyses a priori. This left a final sample of 270 participants (43\% women, $M_{\mathrm{age}}=32$ years; $81.9 \%$ white, $2.2 \%$ Hispanic or Latino, $7 \%$ Black, $6.7 \%$ Asian, $1.9 \%$ other race, $.4 \%$ race not given).

\section{Session One}

During the first session, participants read a story, presented across 26 screens, in which a man named Francis West broke into the homes of two of his neighbors and caused extensive destruction. Participants proceeded through the story at their own pace, and read a variety of details about Francis's actions, such as that he broke down a door, threw a pot of water all over a young girl's computer, and removed precious things from the bedrooms. This story was designed to induce a strong negative impression of Francis (see the Supplemental Material). A photograph of a man labeled "Francis West" was presented on each screen. For each participant, one photograph of a man from a bank of 11 used in prior research (Mann \& Ferguson, 2015; Minear \& Park, 2004) was randomly selected for this purpose, with the other 10 serving as control stimuli during the implicit measures.

After reading the Francis West story, participants completed the first Affect Misattribution Procedure (AMP; Payne, Cheng, Govorun, \& Stewart, 2005). On each of 40 trials, participants were presented with a prime image for $75 \mathrm{~ms}$ (Francis West on 20 trials, control faces on 20 trials). After a $125 \mathrm{~ms}$ blank interval, a Chinese pictograph was 
then presented for $100 \mathrm{~ms}$ before being replaced by a black and white pattern mask. The participants were instructed to judge whether each pictograph was more or less pleasant than the average pictograph, while attempting to not allow the prime stimuli to have any impact on these decisions. The extent to which the primes are systematically associated with pleasantness judgments of the pictographs across trials despite these instructions thus reveals unintentional evaluative processing of the primes (Payne et al., 2005, 2013). The 40 pictographs were drawn from one of two sets (counterbalanced across participants). (Counterbalance condition produced no significant effects, and will not be discussed further.)

Following the first AMP, participants responded to six questions assessing explicit attitudes toward Francis West. They were first asked, "How likable is Francis West?” on a scale from 1 (very unlikable) to 7 (very likable). Then, they were asked to place Francis on 1-7 scales from bad to good, mean to pleasant, disagreeable to agreeable, uncaring to caring, and cruel to kind, in random order. Finally, we collected their email address so as to contact them for the second session (all but 6 provided one), and compensated them $\$ 1.00$.

\section{Session Two}

Approximately 48 hours after the end of their first session, participants were emailed a link inviting them to participate in the second session, for which they would receive a bonus $(\$ 0.50)$ upon completion. They were given 24 hours to participate, with a reminder email after 12 hours (mean interval between sessions $=55.30$ hours, $S D=7.27$, range 47.39 to 73.76 ). (The size of the delay did not impact any of the results.) Participants were randomly assigned to either complete a quiz assessing their recall of the 
events described in the first session before learning a final piece of information about Francis, or to skip directly to learning that final information.

Those in the quiz condition were asked to do their best to recall 10 pieces of information in an open-ended manner by typing their answer into a text box, with up to 25 seconds to answer each. Queried items included such things as the name of the man in the story, and what he threw on the laptop (see the Supplemental Material).

Next, all participants were presented with one of two screens displaying new information about Francis. In the control condition, participants read information consistent with their prior negative impression: Francis had a criminal record, often screamed at kids playing near his property, and broke into the houses in search of valuables and revenge on the children. In the fire rescue story condition, participants instead read information that provided a highly positive reframing of his earlier actions: Francis broke into the homes because he saw that they were on fire, and the "precious things" he removed were the young children who were trapped inside. Participants were asked to think about this new information for at least fifteen seconds before advancing.

Participants then completed the AMP again, identical to the first (except using the remaining ideograph set). Next, they recompleted the explicit attitude scale, and reported whether they spoke Mandarin or Cantonese. The remaining questions were exploratory, and thus not analyzed here. They answered three multiple-choice questions assessing their final interpretations of events in the story, including why Francis threw water (e.g., to put out a fire; to ruin items), why the cat died (e.g., smoke inhalation; injuries from getting stepped on), and what Francis removed from the houses (e.g., children; jewelry). Participants were then asked to identify Francis out of a lineup of the photographs of men 
presented during the study, one of which was Francis West, and the other 10 of which were the control primes. After this, they were asked how confused they were (from 1, not confused at all, to 7, completely confused), whether they thought the story was based on true events (from 1, not at all, to 7, completely), and how they feel right now (from 1, very bad, to 7 , very good). They were also given a manipulation check asking them to identify the final information they had read about Francis, from a set of three options, and then finally reported demographic information, were offered the chance to provide openended feedback to the researchers about the study, and were debriefed and compensated.

\section{Results}

All but four participants correctly identified the final information they had read about Francis West on the manipulation check, demonstrating high levels of attention to the critical Time 2 information. All 270 participants were included in the analyses below, but the results do not meaningfully differ if those four participants are excluded.

\section{Implicit Evaluations}

Implicit evaluations of the primes (Francis West or control faces) were measured as the proportion of pictographs judged to be more pleasant than average within each cell of a 2 (Measurement Time: Time 1, Time 2) x 2 (Prime Person: Francis West, Control Faces) x 2 (Story Condition: Fire Rescue, Control) x 2 (Recall Condition: Quiz Present, Quiz Absent) mixed design, with the first two factors manipulated within-participants.

A mixed-ANOVA revealed that the highest-order significant effect was the interaction between time, prime person, and story condition, $F(1,266)=58.77, p<.001$, $\eta_{\mathrm{p}}^{2}=.181$. Recall condition did not moderate this effect, $F(1,266)=.15, p=.703, \eta_{\mathrm{p}}^{2}=$ .001 , and produced no significant main effect $\left(F[1,266]=.388, p=.534, \eta_{\mathrm{p}}^{2}=.001\right)$ or 
other interactions, including two-way interactions with time $(F[1,266]=.335, p=.563$, $\left.\eta_{\mathrm{p}}^{2}=.001\right)$, prime person $\left(F[1,266]=.530, p=.467, \eta_{\mathrm{p}}^{2}=.002\right)$, or story condition $\left(F[1,266]=.606, p=.437, \eta_{\mathrm{p}}^{2}=.002\right)$ and three-way interactions with time and prime person $\left(F[1,266]=1.893, p=.170, \eta_{\mathrm{p}}^{2}=.007\right)$, time and story condition $(F[1,266]=.216$, $\left.p=.643, \eta_{\mathrm{p}}^{2}=.001\right)$, or prime person and story condition $\left(F[1,266]=.338, p=.561, \eta_{\mathrm{p}}^{2}=\right.$ $.001)$. Figure 1 shows the mean implicit positivity of each prime type across conditions. Examining the three-way effect, we found that the interaction between time and prime person was significant in the fire rescue condition, $F(1,266)=76.56, p<.001, \eta_{\mathrm{p}}^{2}=.223$, such that at Time 1, implicit evaluations of Francis West $(M=.41, S D=.28)$ were significantly less positive than of the control faces $(M=.60, S D=.22), F(1,266)=32.16$, $p<.001, \eta_{\mathrm{p}}^{2}=.108$, but at Time 2 , implicit evaluations of Francis West $(M=.65, S D=$ .26) were significantly more positive than of the control faces $(M=.50, S D=.21)$, $F(1,266)=21.11, p<.001, \eta_{\mathrm{p}}^{2}=.074$. This suggests that reversal of the implicit first impression occurred, and just as strongly as in previous work - the Cohen's $d$ comparing relative implicit preference for Francis over control faces (difference score) at Time 2 in the fire condition versus the control condition was 1.23 , which is comparable to the studies in Mann and Ferguson (2015) that used the same measure (range $1.03-1.15$ ). In the control story condition, there was a marginal interaction between time and prime person, $F(1,266)=3.70, p=.056, \eta_{\mathrm{p}}^{2}=.014$. Implicit evaluations of Francis $(M=.37, S D$ $=.29)$ were significantly less positive than of the control faces $(M=.61, S D=.23)$ at Time $1, F(1,266)=53.61, p<.001, \eta_{p}^{2}=.168$, and this difference was even more pronounced at Time 2 (Francis West: $M=.37, S D=.26$; Control: $M=.68, S D=.21$ ), $F(1,266)=95.96, p<.001, \eta_{\mathrm{p}}^{2}=.265$. 


\section{(INSERT FIGURE 1 HERE)}

We then tested whether individual performance on the recall quiz predicted revision. Two blind coders separately made yes/no determinations for each question as to whether the participant had correctly recalled the information from session one $(98 \%$ agreement). We followed an a priori plan to score answers as "correct" only if both coders judged it as correct. For each participant, we computed recall performance as the total number of correct responses $\left(M_{\text {Recall }}=5.18\right.$ of $10, S D=1.84$, range $\left.0-9\right)$.

Next, we ran a mixed ANOVA on implicit pleasantness in the recall quiz condition, with all interactions and main effects involving time, person prime, story condition, and the continuous measure of recall performance (mean-centered). Results showed that recall performance did not moderate the three-way interaction between time, person prime, and story condition, $F(1,136)=.689, p=.408, \eta_{\mathrm{p}}^{2}=.005$, nor was there a significant main effect of performance $\left(F[1,136]=2.056, p=.154, \eta_{p}^{2}=.015\right)$ or other interactions, including two-way interactions with time $\left(F[1,136]=0.595, p=.442, \eta_{\mathrm{p}}^{2}=\right.$ $.002)$, prime person $\left(F[1,136]=.502, p=.480, \eta_{\mathrm{p}}^{2}=.004\right)$, or story condition $(F[1,136]=$ $\left.0.008, p=.929, \eta_{\mathrm{p}}^{2}<.001\right)$ and three-way interactions with time and prime person $\left(F[1,136]=0.077, p=.782, \eta_{\mathrm{p}}^{2}=.001\right)$, time and story condition $(F[1,136]=.971, p=$ $\left..326, \eta_{\mathrm{p}}^{2}=.007\right)$, or prime person and story condition $\left(F[1,136]=.844, p=.360, \eta_{\mathrm{p}}^{2}=\right.$ $.006)$.

\section{Explicit Evaluations}

Explicit attitudes toward Francis also showed revision in the fire rescue condition. An interaction effect on the mean of the six-item explicit liking scale emerged between time and story condition, $F(1,266)=1084.50, p<.001, \eta_{\mathrm{p}}^{2}=.80$, such that Francis was 
viewed equivalently at Time 1 in the fire condition $(M=1.16, S D=.45)$ and in the control condition $(M=1.28, S D=.70), F(1,266)=2.58, p=.109, \eta_{\mathrm{p}}^{2}=.01$, but at Time 2 was viewed more positively in the fire $(M=5.81, S D=1.47)$ versus control condition $(M$ $=1.21, S D=.45), F(1,266)=1251.40, p<.001, \eta_{\mathrm{p}}^{2}=.82$. The interaction between time and story condition was not moderated by recall quiz condition, $F(1,266)=.260, p=$ $.611, \eta_{\mathrm{p}}^{2}=.001$, and there was also no main effect $\left(F[1,266]=.173, p=.678, \eta_{\mathrm{p}}^{2}=.001\right)$, interaction with time $\left(F[1,266]=.691, p=.406, \eta_{\mathrm{p}}^{2}=.003\right)$, or interaction with story condition $\left(F[1,266]=.855, p=.356, \eta_{\mathrm{p}}^{2}=.003\right)$.

To check for effects of recall performance on explicit evaluations, we conducted a mixed ANOVA in the quiz condition that included all main effects and interactions involving time, story condition, and recall performance. Results showed a marginally significant three-way interaction, $F(1,136)=3.168, p=.077, \eta_{\mathrm{p}}^{2}=.023$, such that there was an interaction between recall performance and story condition at Time $2, F(1,136)=$ $4.943, p=.028, \eta_{\mathrm{p}}^{2}=.035$, but (unsurprisingly) not at Time $1, F(1,136)=.267, p=.606$, $\eta_{\mathrm{p}}^{2}=.002$. In the fire condition, greater recall predicted more positive explicit evaluations of Francis at Time 2, $B=.172, S E=.079, p=.031, \eta_{\mathrm{p}}^{2}=.034$, but there was no relationship between recall and explicit evaluations in the control condition at Time $2, B$ $=-.065, S E=.072, p=.367, \eta_{\mathrm{p}}^{2}=.006$.

\section{Discussion}

These results demonstrate that a route through which negative implicit first impressions have been reversed shortly after formation - reinterpretation (Mann \& Ferguson, 2015) - remains effective even after a delay, despite the potential challenges to such revision through forgetting, trait abstraction, and/or memory consolidation. 
Participants learned new information about a person two days after forming a first impression, which is longer than all studies to date examining whether implicit evaluations of novel targets can be updated and exceeds the delays used in many studies attempting to edit consolidated memories (e.g., Agren et al., 2012; Schiller et al., 2010). Despite this delay, those given reinterpretation information showed a robust reversal of their implicit impression, including those who were not prompted to recall earlier details as well as those who had poor recall. In the control condition, as predicted, implicit evaluations of Francis remained negative over time.

The results show that implicit evaluations track relevant experiences over time, rather than remain stuck in initial experiences. The results also suggest that implicit evaluations do not rely on (only) slow-changing associations (e.g., Rydell \& McConnell, 2006), and that propositional reasoning can impact implicit processes (e.g., De Houwer, 2014; Gawronski \& Bodenhausen, 2006). They are consistent with work on the malleability of implicit evaluations across the lifespan (e.g., Castelli et al., 2010), using experimentally controlled first impressions of novel others to distinguish new learning from reactivation of preexisting contextual attitudes (see Fazio, 2007; Gregg et al., 2006; Cone \& Ferguson, 2015; Mann \& Ferguson, 2015). This suggests that the window for effective reversal of implicit evaluations does not close immediately (cf. Peters \& Gawronski, 2011), at least within a reinterpretation paradigm and with highly relevant new information. Though we can only speculate on the reason for the differences across paradigms, it may be that the form of revision attempted in previous work - simply negating the earlier information - may be less effective without replacing the impression with something new. The rejection of the earlier impression may also be perceived as 
more valid and diagnostic when such a replacement is available, and reinterpretation may constitute an effective case of this combined "subtraction + addition" approach (see discussion in Mann \& Ferguson, 2015). Different types of new information may have unique temporal windows during which revision is possible.

Diagnosticity is an important factor driving explicit (Skowronski \& Carlston, 1989), as well as implicit impressions (Cone \& Ferguson, 2015; Mann \& Ferguson, 2015). In our view, new information that reinterprets earlier information can be construed as diagnostic in that it changes what earlier behaviors diagnose about the person (Mann, Cone, \& Ferguson, 2015); as such, the current work builds on the importance of diagnosticity, demonstrating its importance not just for implicit impression formation, but also for updating over time. The strength of this revision after two days, regardless of recall cues or performance, suggests that whatever initial memory consolidation, trait abstraction, and forgetting of specific details about the source of an impression may occur over the course of at couple days do not preclude the possibility of effective implicit impression change through reinterpretation.

Although the current paradigm used new information that completely explained the initial information, it is also possible that new information would only partially do so, and it may be that explicit recall of the initial details determines extent of updating in such cases. For instance, with more ambiguous new information, explicit recall of the initial details might determine extent of updating (see Wyer 2010, 2016). Collectively, this might suggest that some reactivation of memories for earlier details is important for revision - in line with work on retrieval-driven memory updating (e.g., Lane et al., 2015) - but that new information that strongly reframes earlier details can intrinsically produce 
sufficient reactivation without other external prompting. What is clear, however, is that amount of recall before learning the new information did not impact the extent of revision in this paradigm, suggesting that reinterpretation may be an effective way to update initial impressions even when some forgetting has taken place. It could be that when new, reinterpreting details are provided after a longer delay, the greater abstraction of impressions would make retrieval of the specific behavioral memories required for reinterpretation less likely (Klein et al., 1992; Sherman \& Klein, 1994; see also Hastie \& Park, 1986). Additionally, we obtained a (marginal) interaction involving recall performance on explicit evaluations, and so explicit (vs. implicit) evaluations may be more sensitive to recall, though more research on this is needed. It is also possible that revision through other types of information after a delay (besides details that reframe the earlier impression) is more dependent on recall, which future research might explore.

The role of reactivation of earlier learning for revision of various types of responses is a topic of ongoing discussion (Mann, Cone, \& Ferguson, 2015; Lane et al., 2015). Future research can more fully test the range of the temporal window during which implicit impression updating is possible, as well as identify cases in which memory recall may moderate revision. For now, our findings add to the emerging literature on when and how implicit first impressions can be updated. 


\section{References}

Agren, T., Engman, J., Frick, A., Bjorkstrand, J., Larsson, E. M., Furmark, T., \& Fredrikson, M. (2012). Disruption of reconsolidation erases a fear memory trace in the human amygdala. Science, 337(6101), 1550-1552.

http://doi.org/10.1126/science. 1223006

Babey, S. H., Queller, S., \& Klein, S. B. (1998). The role of expectancy violating behaviors in the representation of trait knowledge: A summary-plus-exception model of social memory. Social Cognition, 16(3), 287-339.

Bouton, M. E. (1994). Context, ambiguity, and classical conditioning. Current Directions in Psychological Science, 3(2), 49-53. http://doi.org/10.1111/14678721.ep10769943

Castelli, L., Carraro, L., Gawronski, B., \& Gava, K. (2010). On the determinants of implicit evaluations: When the present weighs more than the past. Journal of Experimental Social Psychology, 46(1), 186-191.

http://doi.org/10.1016/j.jesp.2009.10.006

Castelli, L., Zogmaister, C., Smith, E. R., \& Arcuri, L. (2004). On the automatic evaluation of social exemplars. Journal of Personality and Social Psychology, 86(3), 373.

Cone, J., \& Ferguson, M. J. (2015). He did what? The role of diagnosticity in revising implicit evaluations. Journal of Personality and Social Psychology, 108, 37-57. http://doi.org/10.1037/pspa0000014

De Houwer, J. (2014). A propositional model of implicit evaluation. Social and 
Personality Psychology Compass, 8(7), 342-353.

http://doi.org/10.1111/spc3.12111

Devine, P. G. (1989). Stereotypes and prejudice: Their automatic and controlled components. Journal of Personality and Social Psychology, 56(1), 5-18. http://doi.org/10.1037/0022-3514.56.1.5

Dudai, Y. (2004). The neurobiology of consolidations, or, how stable is the engram? Annual Review of Psychology, 55(1), 51-86. http://doi.org/10.1146/annurev.psych.55.090902.142050

Dunham, Y., Baron, A. S., \& Banaji, M. R. (2008). The development of implicit intergroup cognition. Trends in Cognitive Sciences, 12, 248-253.

Fazio, R. H. (2007). Attitudes as object-evaluation associations of varying strength. Social Cognition, 25, 603- 637. http://dx.doi.org/10.1521/soco .2007.25.5.603

Gawronski, B., \& Bodenhausen, G. V. (2006). Associative and propositional processes in evaluation: An integrative review of implicit and explicit attitude change. Psychological Bulletin, 132(5), 692-731. http://doi.org/10.1037/00332909.132.5.692

Gawronski, B., \& Cesario, J. (2013). Of mice and men: What animal research can tell us about context effects on automatic responses in humans. Personality and Social Psychology Review, 17(2), 187-215. http://doi.org/10.1177/1088868313480096

Gregg, A. P., Seibt, B., \& Banaji, M. R. (2006). Easier done than undone: Asymmetry in the malleability of implicit preferences. Journal of Personality and Social Psychology, 90(1), 1-20. http://doi.org/10.1037/0022-3514.90.1.1

Hastie, R., \& Kumar, P. A. (1979). Person memory: Personality traits as organizing 
principles in memory for behaviors. Journal of Personality and Social Psychology, 37, 25-38.

Hastie, R., \& Park, B. (1986). The relationship between memory and judgment depends on whether the judgment task is memory-based or on-line. Psychological Review, 93(3), 258.

Kawakami, K., Phills, C. E., Steele, J. R., \& Dovidio, J. F. (2007). (Close) distance makes the heart grow fonder: Improving implicit racial attitudes and interracial interactions through approach behaviors. Journal of Personality and Social Psychology, 92(6), 957-971. http://doi.org/10.1037/0022-3514.92.6.957

Klein, S. B., Loftus, J., Trafton, J. G., \& Fuhrman, R. W. (1992). Use of exemplars and abstractions in trait judgments: A model of trait knowledge about the self and others. Journal of Personality and Social Psychology, 63(5), 739.

Kumkale, G. T., \& Albarracín, D. (2004). The sleeper effect in persuasion: A metaanalytic review. Psychological Bulletin, 130(1), 143-172. http://doi.org/10.1037/0033-2909.130.1.143

Lane, R. D., Ryan, L., \& Nadel, L. (2015). Memory reconsolidation, emotional arousal and the process of change in psychotherapy: New insights from brain science. Behavioral and Brain Sciences, 38, 1-64.

Mann, T., Cone, J., \& Ferguson, M. J. (2015). Social-psychological evidence for the effective updating of implicit attitudes. Behavioral and Brain Sciences, 38, 32-33

Mann, T. C., \& Ferguson, M. J. (2015). Can we undo our first impressions? The role of reinterpretation in reversing implicit evaluations. Journal of Personality and Social Psychology, 108(6), 823-849. http://doi.org/10.1037/pspa0000021 
McCarthy, R. J., \& Skowronski, J. J. (2011). What will Phil do next? Journal of Experimental Social Psychology, 47(2), 321-332.

McConnell, A. R., \& Rydell, R. J. (2014). The systems of evaluation model: A dualsystems approach to attitudes. In J. Sherman, B. Gawronski, \& Y. Trope (Eds.), Dual process theories of the social mind (pp. 204-217). New York: Guilford.

McGaugh, J. L. (2000). Memory - a century of consolidation. Science, 287(5451), 248251. http://doi.org/10.1126/science.287.5451.248

Minear, M., \& Park, D. C. (2004). A lifespan database of adult facial stimuli. Behavior Research Methods, Instruments, \& Computers, 36, 630-633.

Payne, B. K., Brown-Iannuzzi, J., Burkley, M., Arbuckle, N. L., Cooley, E., Cameron, C. D., \& Lundberg, K. B. (2013). Intention Invention and the Affect Misattribution Procedure: Reply to Bar-Anan and Nosek (2012). Personality and Social Psychology Bulletin, 39(3), 375-386. http://doi.org/10.1177/0146167212475225

Payne, B. K., Cheng, C. M., Govorun, O., \& Stewart, B. D. (2005). An inkblot for attitudes: Affect misattribution as implicit measurement. Journal of Personality and Social Psychology, 89(3), 277-293. http://doi.org/10.1037/00223514.89.3.277

Peters, K. R., \& Gawronski, B. (2011). Are we puppets on a string? Comparing the impact of contingency and validity on implicit and explicit evaluations. Personality and Social Psychology Bulletin, 37(4), 557-569. http://doi.org/10.1177/0146167211400423

Pratkanis, A. R., Greenwald, A. G., Leippe, M. R., \& Baumgardner, M. H. (1988). In 
search of reliable persuasion effects: III. The sleeper effect is dead: Long live the sleeper effect. Journal of Personality and Social Psychology, 54, 203-218.

Rudman, L. A., Phelan, J. E., \& Heppen, J. B. (2007). Developmental sources of implicit attitudes. Personality and Social Psychology Bulletin, 33, 1700-1713.

Rule, N. O., Ambady, N., Adams, R. B., Jr., Ozono, H., Nakashima, S., Yoshikawa, S., \& Watabe, M. (2010). Polling the face: Prediction and consensus across cultures. Journal of Personality and Social Psychology, 98, 1-15.

Rydell, R. J., \& McConnell, A. R. (2006). Understanding implicit and explicit attitude change: A systems of reasoning analysis. Journal of Personality and Social Psychology, 91(6), 995-1008. http://doi.org/10.1037/0022-3514.91.6.995

Schiller, D., Kanen, J. W., LeDoux, J. E., Monfils, M. H., \& Phelps, E. A. (2013). Extinction during reconsolidation of threat memory diminishes prefrontal cortex involvement. Proceedings of the National Academy of Sciences, 110(50), 20040 20045. http://doi.org/10.1073/pnas.1320322110

Schiller, D., Monfils, M. H., Raio, C. M., Johnson, D. C., LeDoux, J. E., \& Phelps, E. A. (2010). Preventing the return of fear in humans using reconsolidation update mechanisms. Nature, 463(7277), 49-53.

Skowronski, J. J., \& Carlston, D. E. (1989). Negativity and extremity biases in impression formation: A review of explanations. Psychological Bulletin, 105(1), $131-142$.

Sherman, J. W., \& Klein, S. B. (1994). Development and representation of personality impressions. Journal of Personality and Social Psychology, 67(6), 972-983.

Todorov, A., \& Uleman, J. S. (2002). Spontaneous trait inferences are bound to actors' 
faces: Evidence from a false recognition paradigm. Journal of Personality and Social Psychology, 83(5), 1051-1065. http://doi.org/10.1037//0022-

3514.83 .5 .1051

Van Dessel, P., De Houwer, J., Gast, A., \& Smith, C. T. (2015). Instruction-based approach-avoidance effects: Changing stimulus evaluation via the mere instruction to approach or avoid stimuli. Experimental Psychology, 62, 161-169. http://dx.doi.org/10.1027/ 1618-3169/a000282

Van Dessel, P., De Houwer, J., Gast, A., Smith, C. T., \& De Schryver, M. (2016). Instructing implicit processes: When instructions to approach or avoid influence implicit but not explicit evaluation. Journal of Experimental Social Psychology, 63(C), 1-9. http://doi.org/10.1016/j.jesp.2015.11.002

Westfall, J. (2015). PANGEA: Power ANalysis for GEneral Anova designs (Working paper). Retrieved from: http://jakewestfall.org/publications/pangea.pdf

Wilson, T. D., Lindsey, S., \& Schooler, T. Y. (2000). A model of dual attitudes. Psychological Review, 107(1), 101.

Woud, M. L., Maas, J., Becker, E. S., \& Rinck, M. (2013). Make the manikin move: Symbolic approach-avoidance responses affect implicit and explicit face evaluations. Journal of Cognitive Psychology, 25(6), 738-744. http://doi.org/10.1080/20445911.2013.817413

Wyer, N. A. (2010). You never get a second chance to make a first (implicit) impression: The role of elaboration in the formation and revision of implicit impressions. Social Cognition, 28(1), 1-19.

Wyer, N. A. (2016). Easier done than undone... by some of the people, some of the time: 
The role of elaboration in explicit and implicit group preferences. Journal of Experimental Social Psychology, 63, 77-85.

Zanon, R., De Houwer, J., Gast, A., \& Smith, C. T. (2014). When does relational information influence evaluative conditioning? The Quarterly Journal of Experimental Psychology, 67(11), 2105-2122.

http://doi.org/10.1080/17470218.2014.907324 


\section{Footnotes}

${ }^{1}$ We thank a reviewer for bringing this argument to our attention.

${ }^{2}$ We believe that in hindsight, we performed this power analysis incorrectly;

however, the sample size is consistent with prior studies using this same paradigm (Mann \& Ferguson, 2015), and Westfall's (2015) PANGEA power analysis tool

(http://jakewestfall.org/pangea/) suggests that the power for this 4-way design with a total sample of 260 participants is estimated at $87.2 \%$ under default variance component assumptions, which is above our target of $80 \%$ power. 


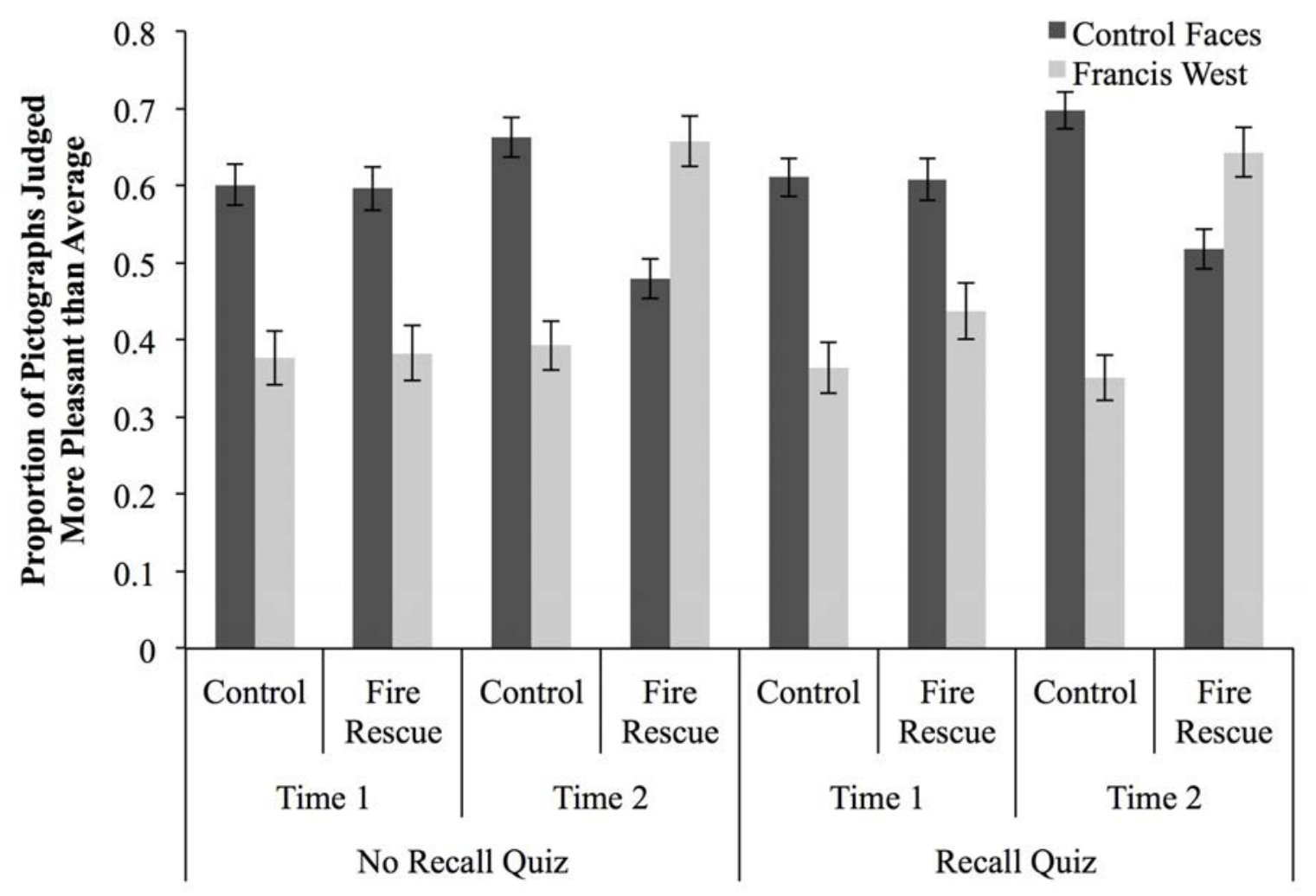

Fig. 1. Mean proportion of pictographs judged to be more pleasant than the average pictograph, by quiz condition, time, story condition, and person prime. Error bars are standard errors. 